\title{
Exploring cytotoxic drugs residues in hospital effluents: a narrative review
}

$\underline{\text { Farshad Hashemian }}^{1}$, Elnaz Roohi $^{1}$

${ }^{1}$ Associate Professor, Department of Clinical Pharmacy, Faculty of Pharmacy, Tehran Medical Sciences, Islamic Azad University, Tehran, Iran

${ }^{I}$ PhD, Department of Clinical Pharmacy, Faculty of Pharmacy, Tehran Medical Sciences, Islamic Azad University, Tehran, Iran

\begin{abstract}
Background: Cytotoxic waste management is one of the significant issues in healthcare system. The aim of the present study was to review studies conducted on investigation of possible levels of cytotoxic drug residues in hospital effluents.

Materials and methods: All peer-reviewed journal articles on investigation of possible levels of cytotoxic drugs residues in hospital effluents which were published before May 2019 were investigated. 51 publications which were mostly published between 2011 and 2016 were included.

Results: Anticancer medication continue to enter hospital effluents and urbane wastewaters. Hospital effluents seem to be one of the main sources of water contamination in this regard. Cytotoxic drugs and their metabolites are detected in hospital effluents in different countries across the globe. Platinum-based antineoplastic drugs, methotrexate, cyclophosphamide, ifosfamide and tamoxifen were found with higher concentrations across different studies.

Conclusion: Hospital waste management is one of the most important issues in health care system. According to the results of the present study, cytotoxic drugs residues are detected in the effluents of oncology wards of the investigated hospitals. Therefore, establishment of strict rules and regulations, provision of cytotoxic waste disposal and removal for the purpose of inactivating cytotoxic drugs in hospital effluents prior to entrance of the effluents to the sewage treatment systems is mandatory.
\end{abstract}

Keywords: Hospital effluents, Antineoplastic drugs, Cytotoxic drugs, Hospital waste.

Cited as: Hashemian F, Roohi E. Exploring cytotoxic drugs residues in hospital effluents: a narrative review. Medical Science Journal of Islamic Azad University, Tehran Medical Branch 2019; 29(4): 284-295.

Correspondence to: Farshad Hashemian

Tel: +989123183018

E-mail: hashemian.f@iaups.ac.ir

ORCID ID: 0000-0003-0016-3697

Received: 25 Oct 2019; Accepted: 25Aug 2019 
مجله علوم يزشكى دانشكاه آزاد اسلامى

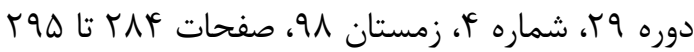

Review

Article

\section{بررسى ميزان باقى مانده داروهاى ضد سرطان در پسآب بيمارستانى: يك مطالعه مرورى}

\section{فرشاد هاشميان'، الناز روحى؟}

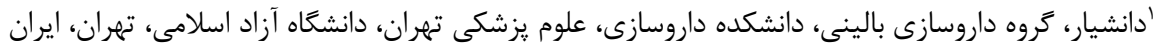

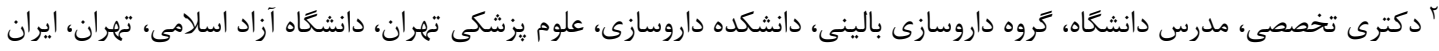

سابقه و هدف: دفع زبالههاى سيتوتوكسيك در بيمارستانها همواره از مسائل حائز اهميت است. هدف از مطالعه حاضر، بررسى

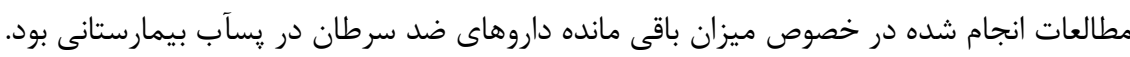

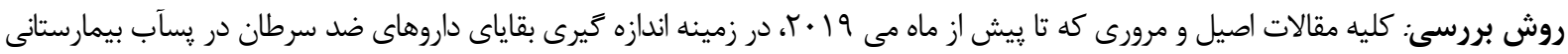

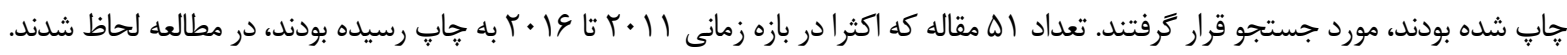

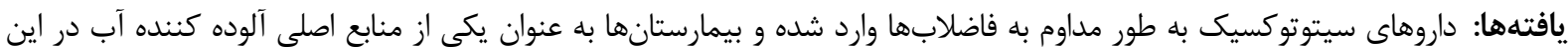

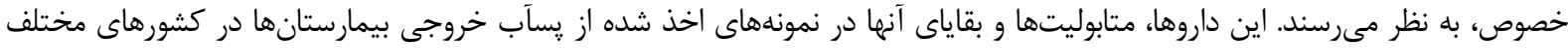

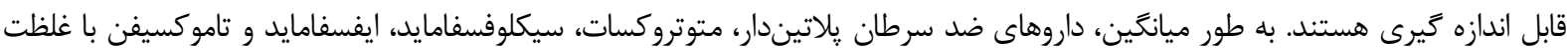

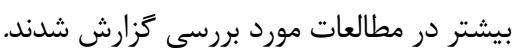

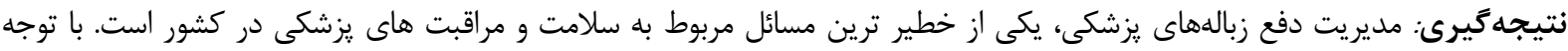

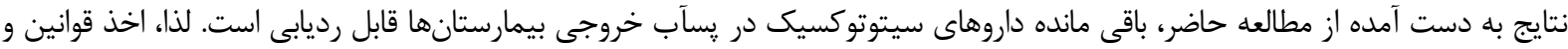

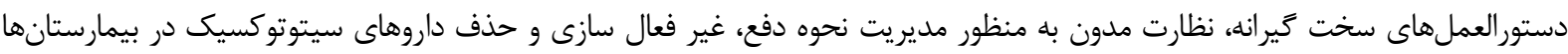
يريش از تخليه آنها به سيستم فاضلاب شهرى ضرورى به نظر مى نهرسد.

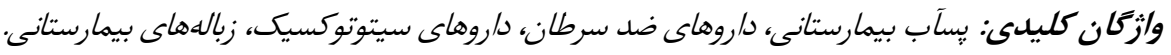

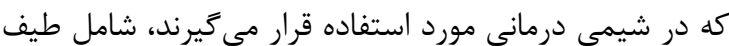

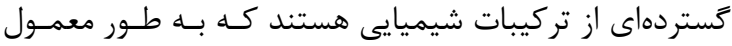

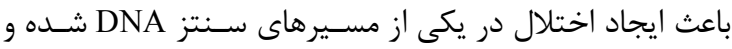

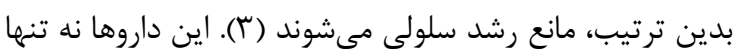

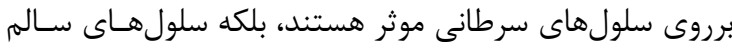

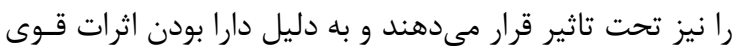

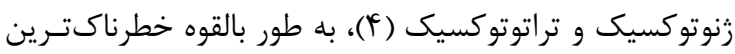

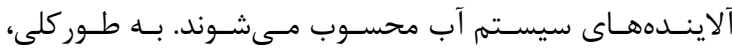

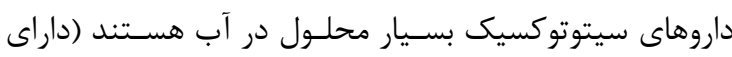
log Kow
توليد فاضلاب بيمارستانى طى سالهاى اخير به دليل يُيشرفت و توسعه خدمات بزشكى افزايش خشم گيرى داشته است (1).

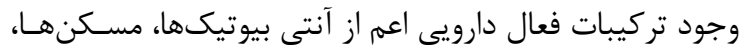
داروهاى مورد استفاده در بيمارىهاى اعصاب و وروان، داروهاى

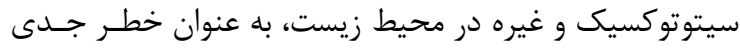

آدرس نويسنده مسئول: تهران، دانشگاه آزاد اسلامى، دانشكده داروسازى، گروه داروسازى بـالينى، فرشـاد هاشميان (email: hashemian.f@iaups.ac.ir) ORCID ID: 0000-0003-0016-3697 تاريخ دريافت مقاله:

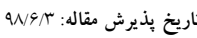




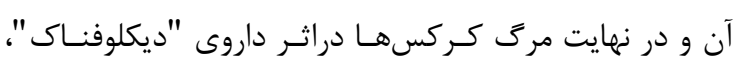

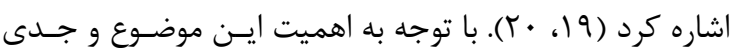

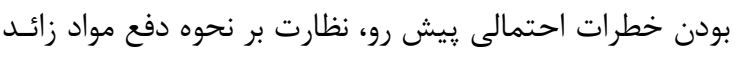

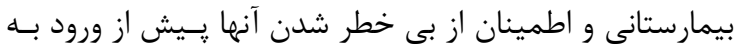
سيستم فاضلاب شهرى ضرورى به نظر مىرسد. از آنجايى كـهـ آنهان

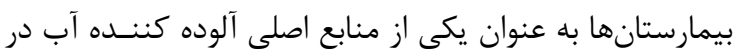

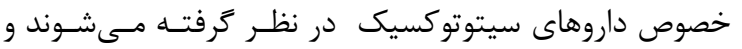
تماس با اين دسته از داروها براى سلامت انسان بسيار زيان بار

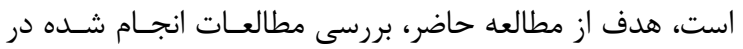

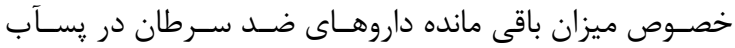

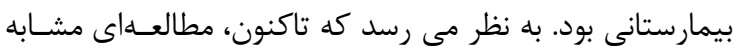

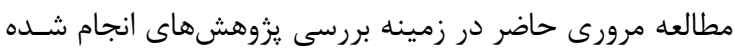

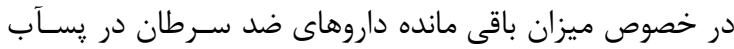

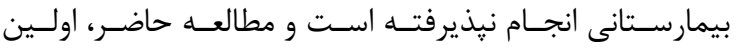
ئروهش در اين خصوص است.

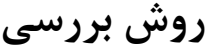

مطالعه مرورى حاضر از نوع روايتى بود و كليه مقالات اصيل و

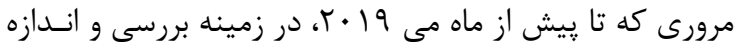

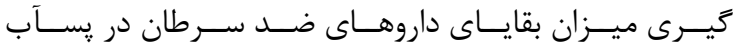
بيمارستانى در مجلاتى با معيـار داورى "peer review" جـاب

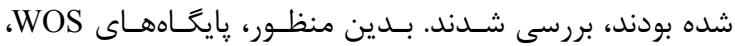
،SID ،ISC ،Google Scholar ،Scopus ،Medline ،Pubmed

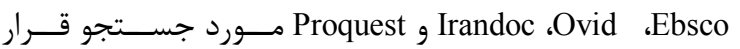
كرفتند. بدين منظور، در پاييز و زمستان لوجّا، در موتورهـاى

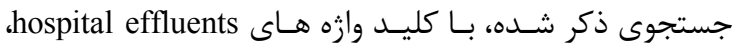
anti-cancer ،cytotoxic drugs hospital wastewater Medical cytotoxic waste و medication

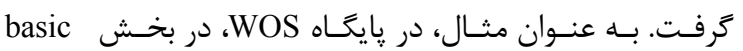

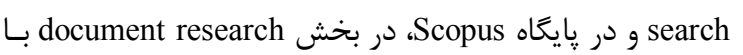
استفاده از كليدوازه ها، جستجو انجام شد. جسـتجو در بِايخــاه

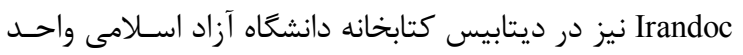

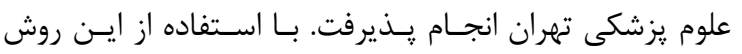

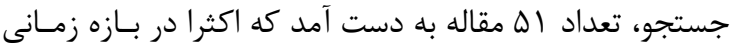

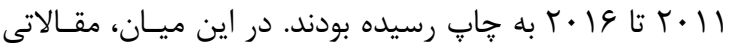
كه صـرفا بـه بررسى بقايـاى داروهـاى سيتوتوكسـيك در آب آبـ

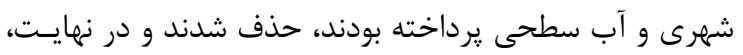

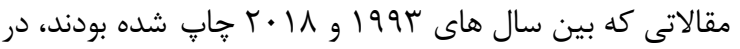

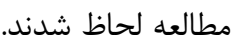

ولى از ديدكاه فارماكولوزيك مفيد اسـت. زيـرا باعـث افـزايش

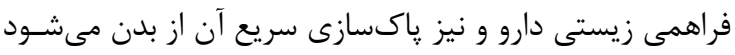

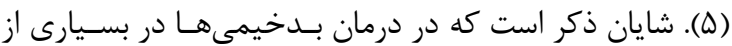

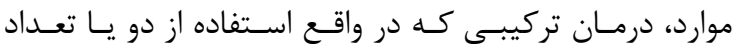
بيشترى داروى سيتوتوكسيك به صورت همزمان اسـت، مـورد دارد

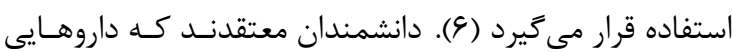

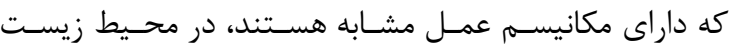

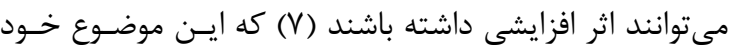

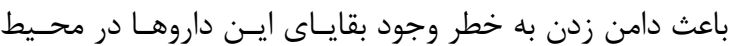

$$
\text { زيست و سيستم آب و فاضلاب مى شئود. }
$$

بخشى از داروهايى كه هر روز توسط مردم مصرف مى شود، بــهـ

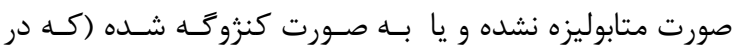
واقع، احتمال فعال شدن مجدد آن ها وجود دارد) دفع شـده و

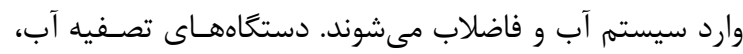

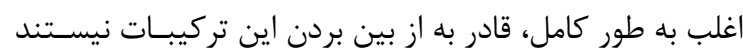

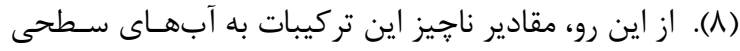

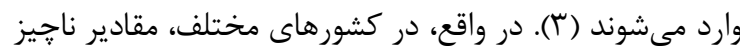

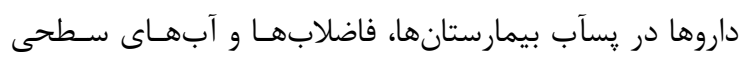

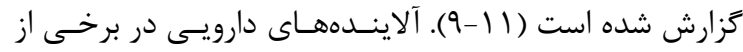

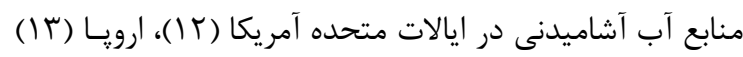

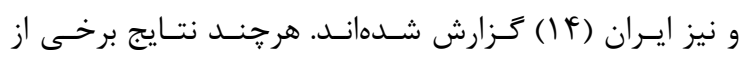

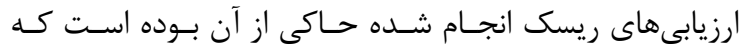

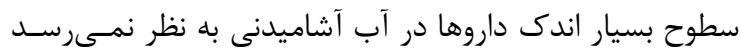

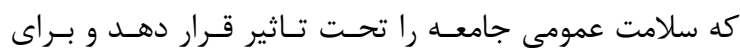

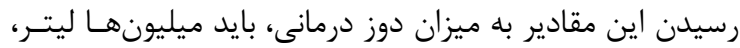

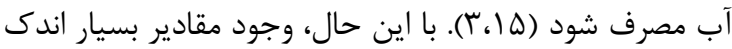

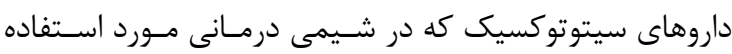

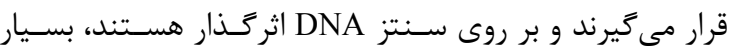

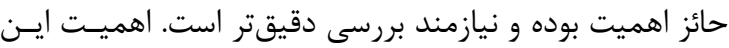

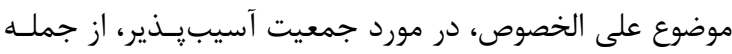

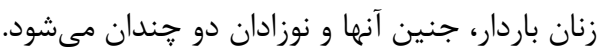

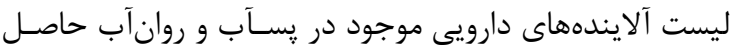

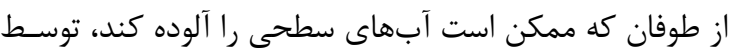

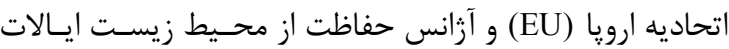

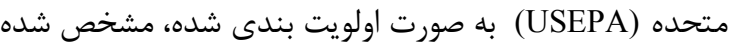

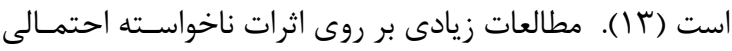

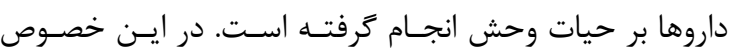

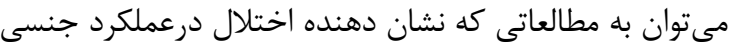

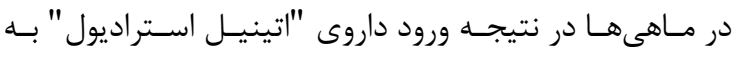
محيط زيست (1|-9|1) و اختلال در عملكرد كليسه و نارسـايى 
على رغم افزايش غلظت باقى مانده داروهاى سيتوتوكسيك در

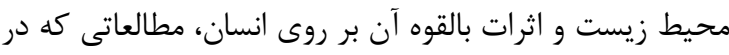
آنها ميزان داروهاى سيتوتوكسيك در يسآب بيمارستانى اندازه كيرى شده باشد، محدود است و بيشـتر مطالعـات ايسن دســــ دئه

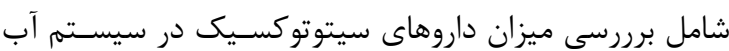
شهرى و نيز آب سطحى است.

مطالعات انجام شده در خصوص باقى مانده داروهاى ضد سرطان در يسآب بيمارستانى در ارويا

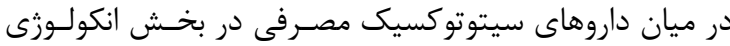

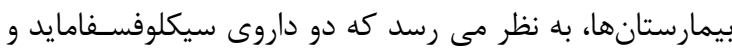

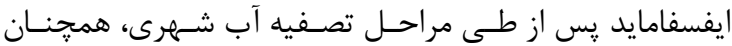

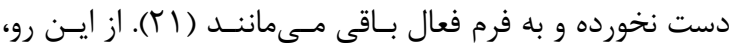

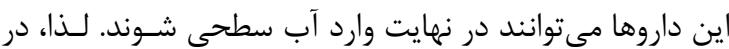

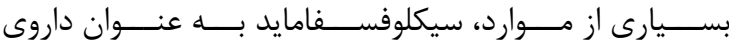

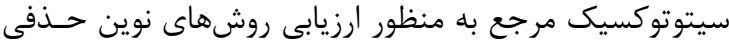
داروهاى سيتوتوكسيك و نيز ديكر داروهـا در سيسـتم تصـفيه آب به كار مىرود (YY). در مطالعـات انجـام شــده در آلمـان و

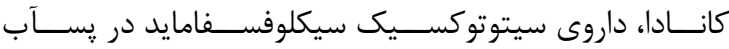

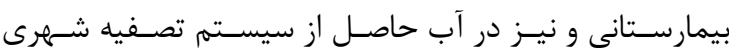

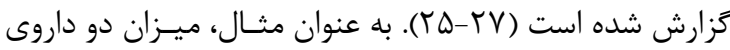

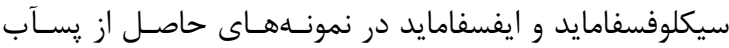

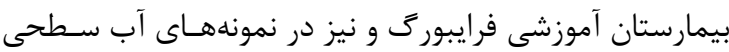

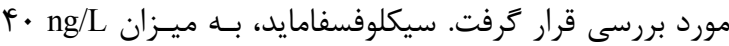

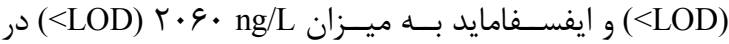
يسآب بيمارستان آموزشى فرايبورى كزارش شد. در نمونههاى

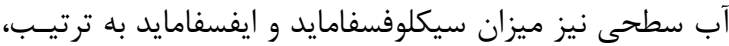
(YQ) (Y).

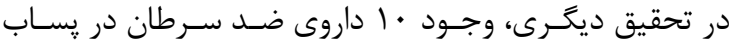

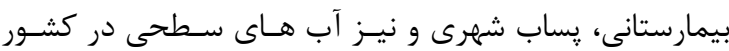

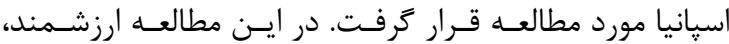
خطرات بالقوه زيست محيطى ناشى از وجود بقاياى اين داروها

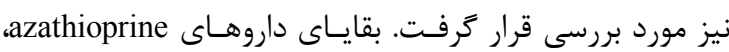
،methotrexate apaclitaxel docetaxel ،etoposide ciprofloxacin و در يســآب بيمارستانى و نيز در پِاب ورودى به سيستم فاضـلاب شـهرى مورد شناسايى قرار گرفت. البته بقاياى اكثر داروهاى ذكر شده

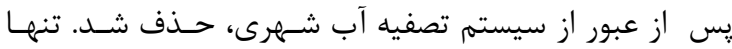

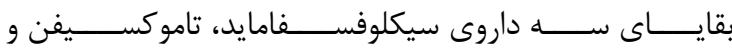
سييروفلوكساسين در يسآب حاصل از تصفيه آب شهرى و نيـز در آب سطحى مورد شناسايى قراركرفت. غلظت اين داروها بــــ
زباله هاى سيتوتوكسيك در بيمارستانها و بــاقى مانــده داروهاى ضد سرطان در يسآب بيمارستانى داروهاى ضد سرطان به طورمداوم به فاضلاب بيمارسـتانهـا و ودان

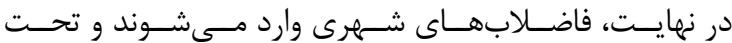
فرآيندهاى معمول تصفيهاى قرار مسى گيرنسـ. تحقيقـات نشـان

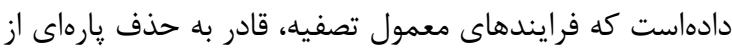

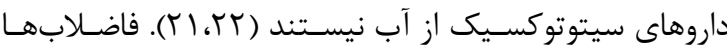
حاوى تركيبات بيجيدهايى شامل داروها، متابوليت آنها و مــواد

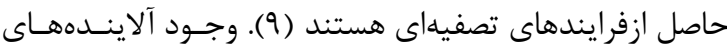

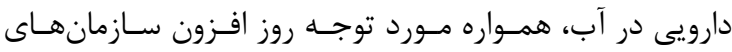

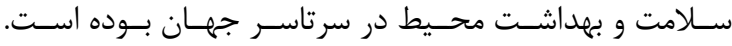

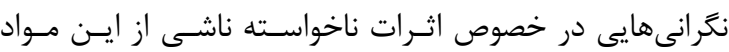

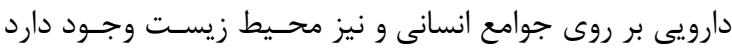

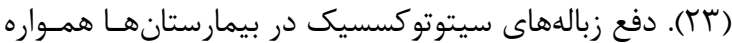

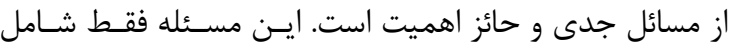

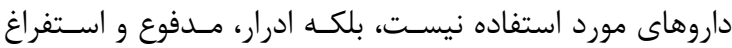
بيماران تحت شيمى درمانى را نيز در برمى گيرد. در سالهـاى

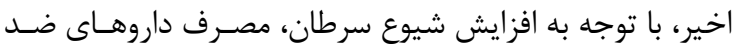

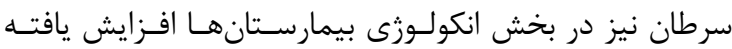

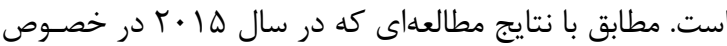

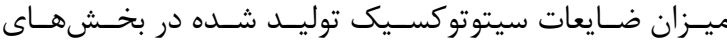

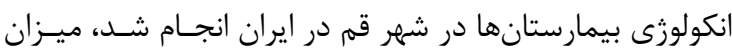

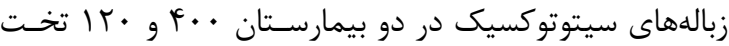

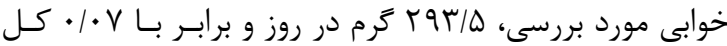

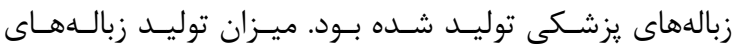

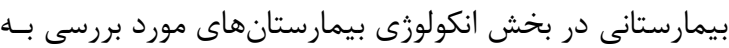

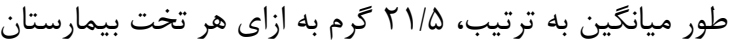

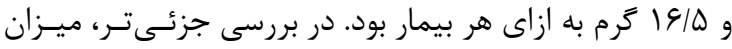

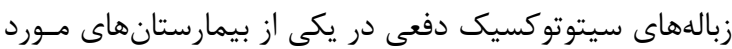

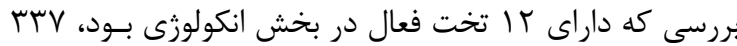

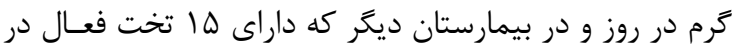

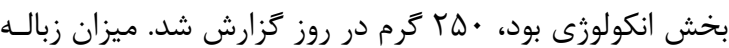

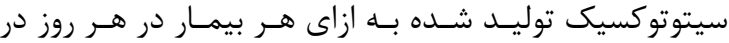

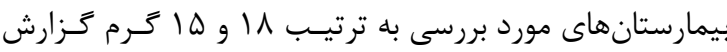

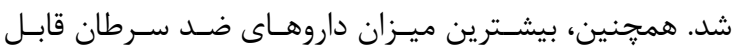
رديابى در خصوص سيكلوفسفامايد، ايفسفامايد و مسنا گزارش

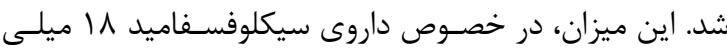

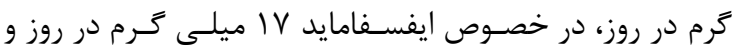
براى داروى مسنا ها ميلى زَرم در روز گزارش شد (YY). 
نتايج سه مطالعه ذكر شده در بالا هم سو با يكديكر بـوده و در

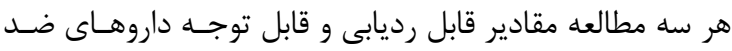

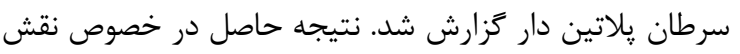

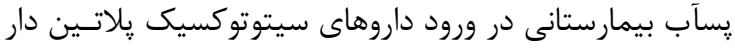

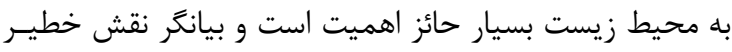

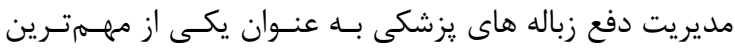
مسائل مربوط به سلامت و مراقبتهاى يزشكى در حال حال حاضـر

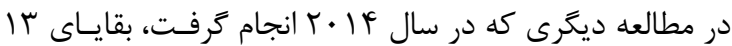

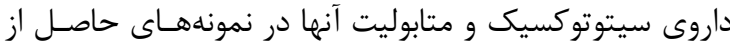

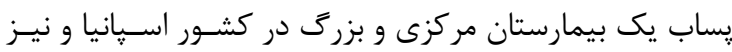
نمونههاى حاصل از آب خروجى از سيستم تصفيه با استفاده از برن روش solid-phase extraction-liquid chromatographytandem mass spectrometry (SPE-LC-MS/MS)

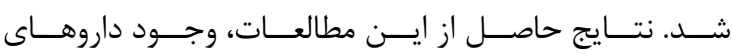

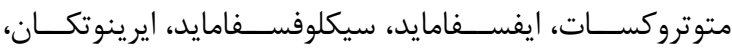
دوكسوروبيسـين، كايسـيتاباين، تاموكسـيفن و متابوليـتهــاى

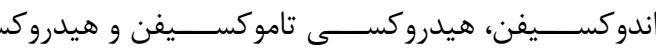

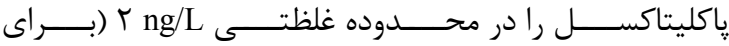

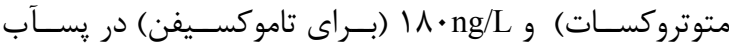

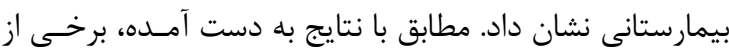

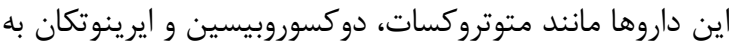
طرز موثرى توسط سيستم تصفيه آب از بـين مسرونــد (آم).

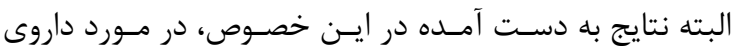

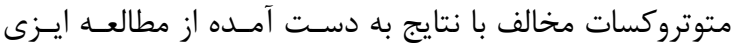

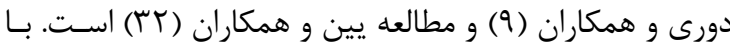

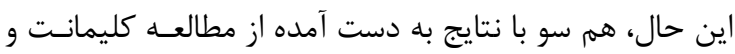

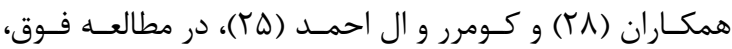

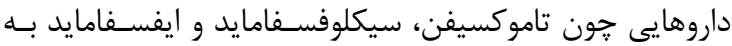

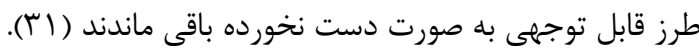

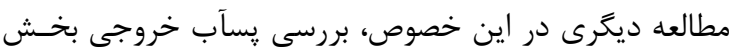

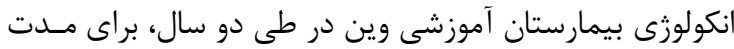

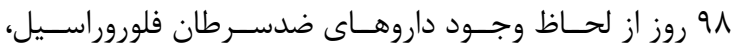
دوكسوروبيسـين، إيسى روبيسـين و دانوروبيسـين بـود. نتـايج

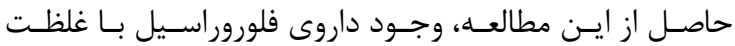

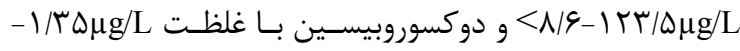

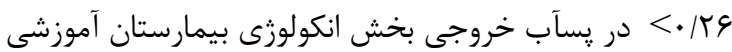

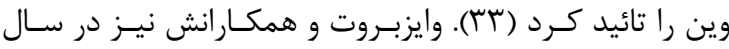

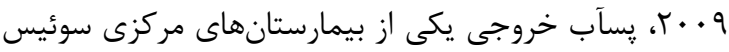

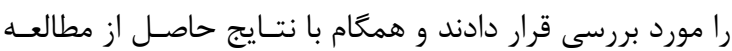

ترتيب در محسدوده كزارش شد. دو داروى تاموكسيفن و سييروفلوكساسين به طور

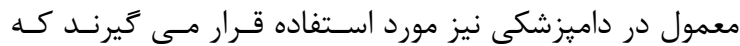

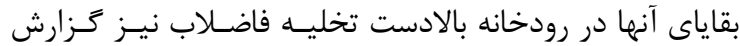

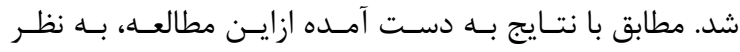
مىرسد كه دو داروى ذكر شده بدون تغيير، از سيستم تصفيه

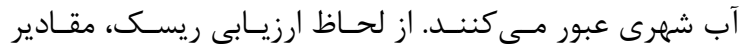

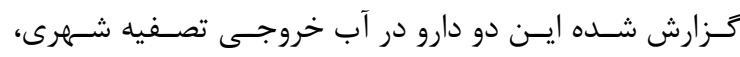

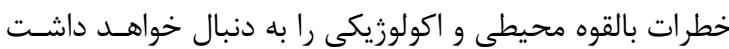

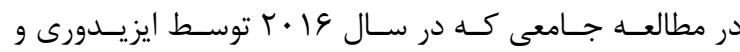

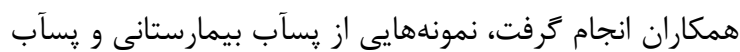

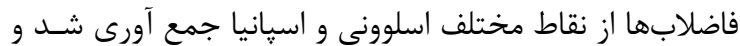
از لحاظ وجود ب r نوع داروى ضدسرطان، متابوليتهاى آنها و و

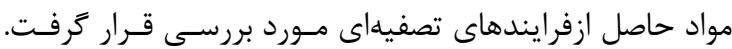

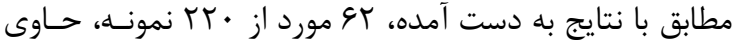

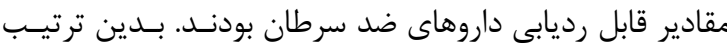

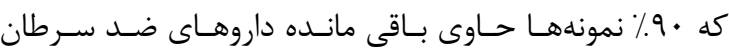

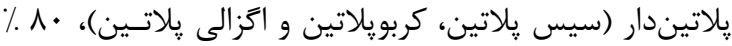

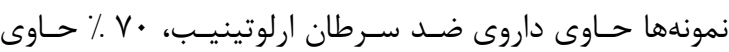

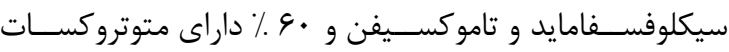

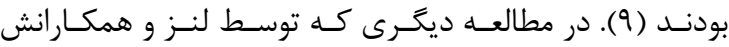

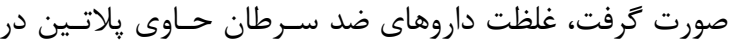

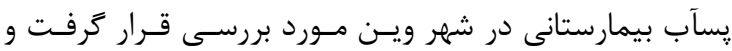

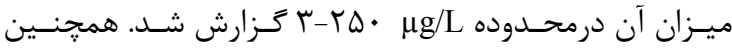

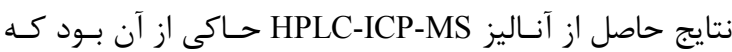

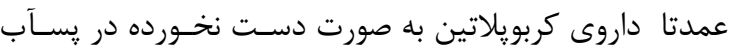

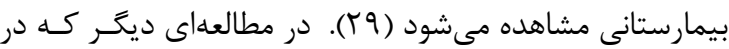

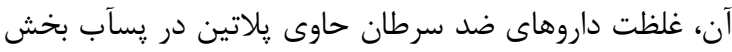

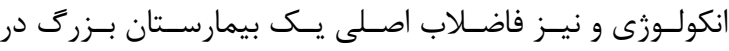
انعلستان در مدت زمانى ب هفته بررسى شد. غلظت ائل اين داروها

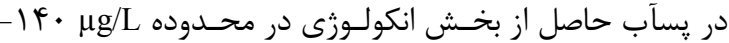

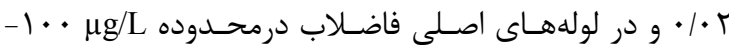
ץ.

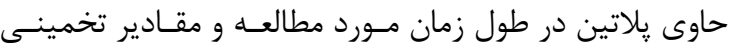

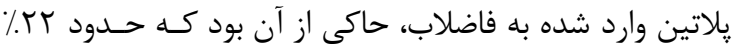

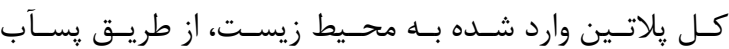

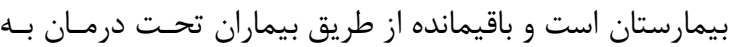
محيط وارد مىشود (·r). 
بر روى داروهاى ضدسرطان يلاتين دار صورت كرفتـ مسىتـوان نتيجه كيرى كرد كه هم سو با نتايج بـه دسـت آمــده از مطالعـهـ

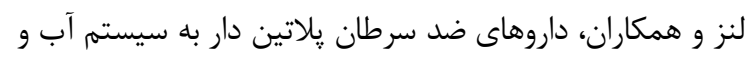

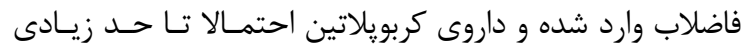

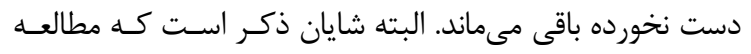

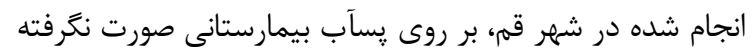

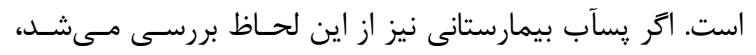

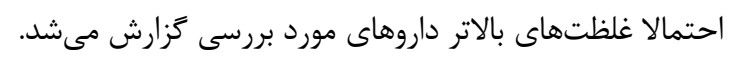

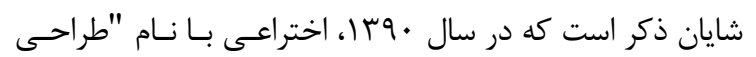

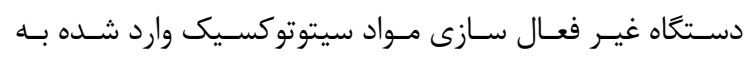

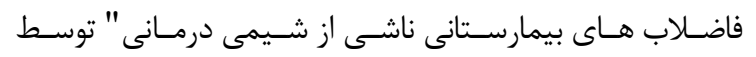

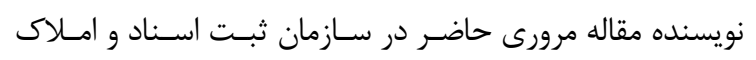
كشور ثبت شده است (YV).

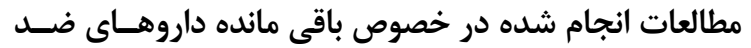

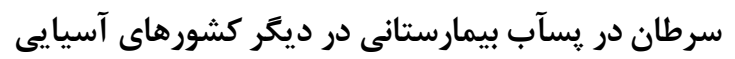

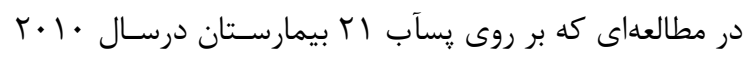

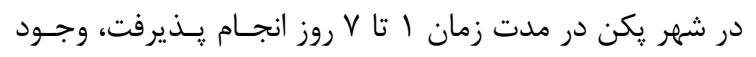

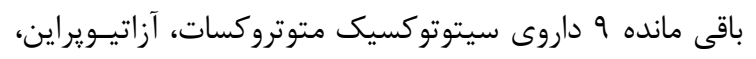

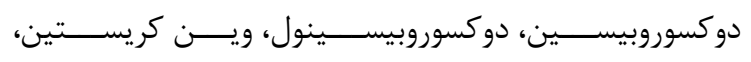

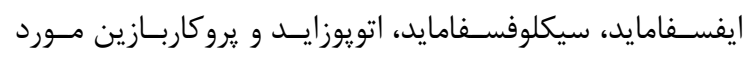

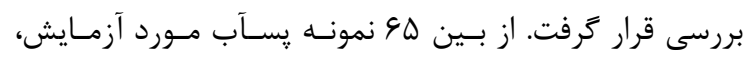

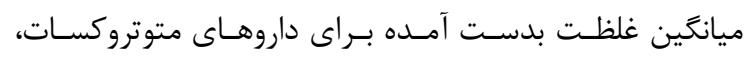

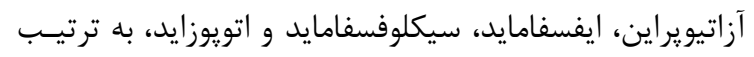

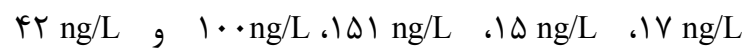
كزارش شد. همجنين، باقى مانـده داروهـاى دوكسوروبيسـين،

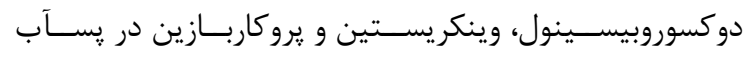

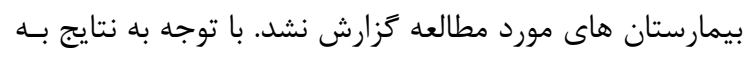

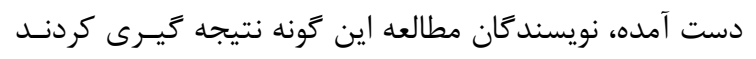

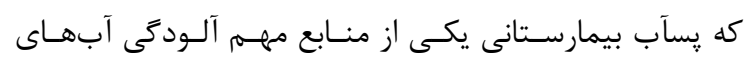

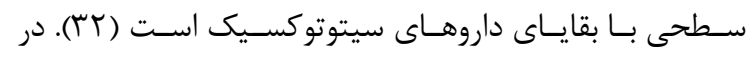

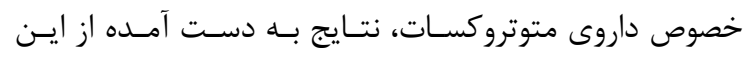

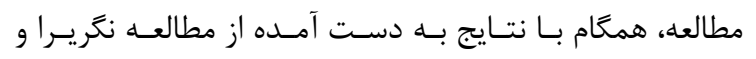

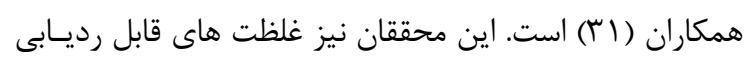

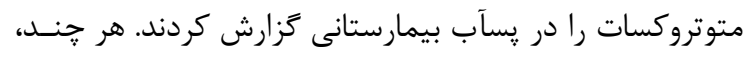

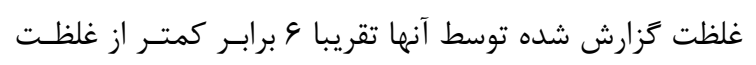

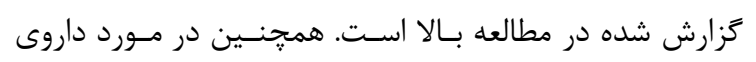

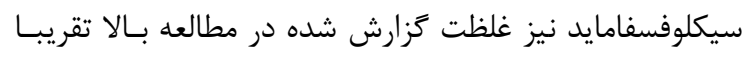

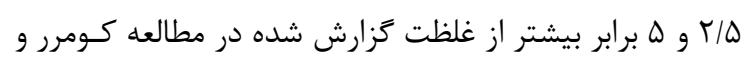

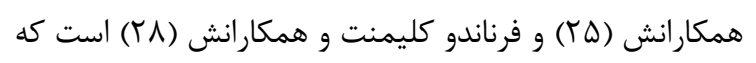

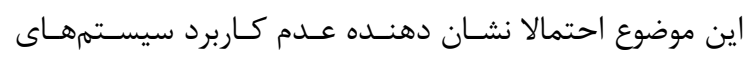

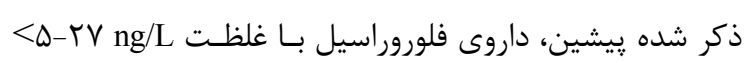

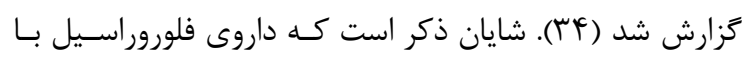

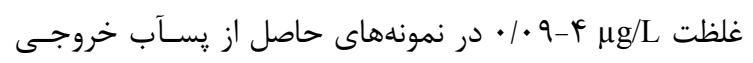

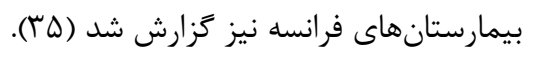
مطالعات انجام شده در خصوص باقى مانده داروهاى ضد ضد ندان سرطان در پِآب بيمارستانى در ايران

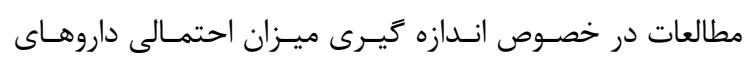

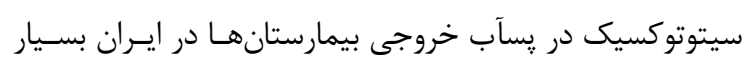

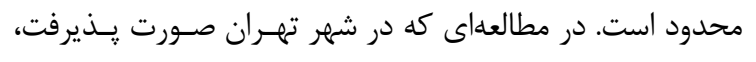

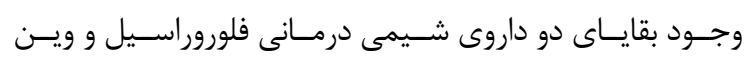

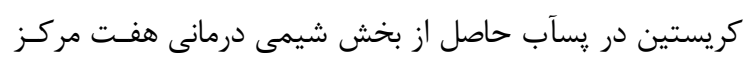

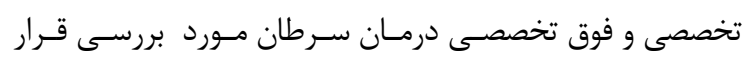

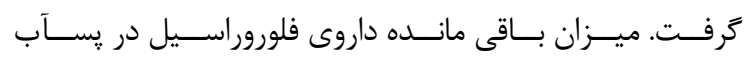
بيمارستانى، در محسدوده

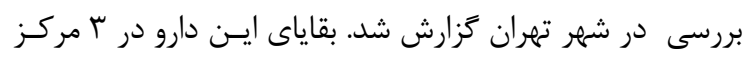

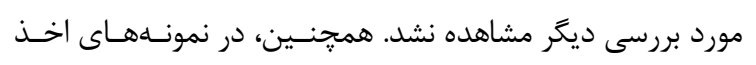

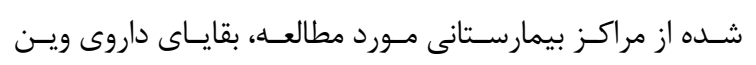

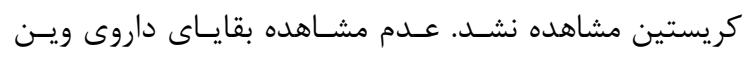

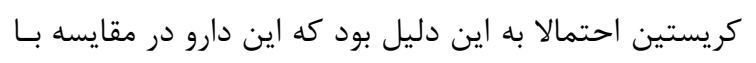

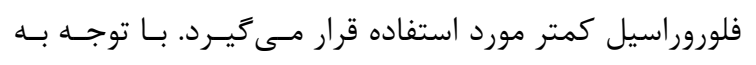

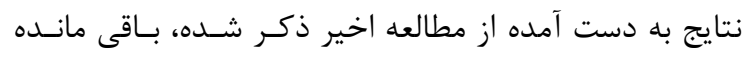

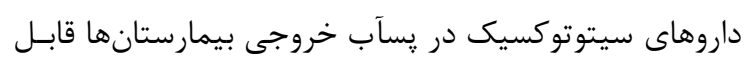

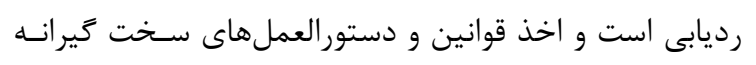

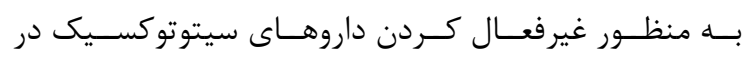

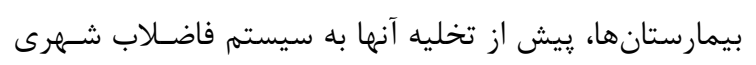
ضرورى به نظر مىرسد (ع)ى).

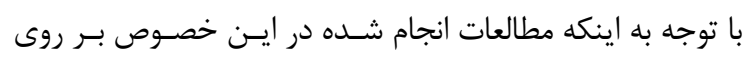

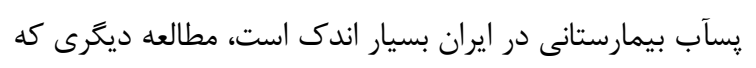

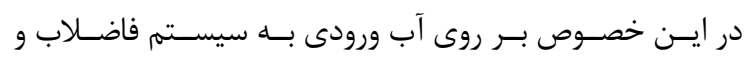
خروجى از آن انجام شد، ذكـر مسى شــود. ايسن مطالعـه در سـال

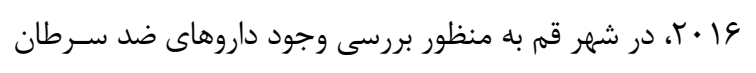

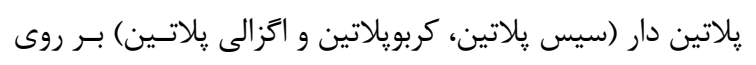

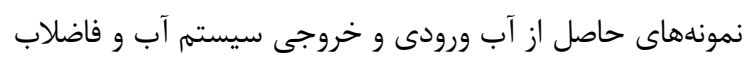

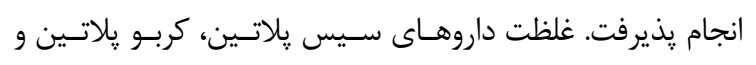

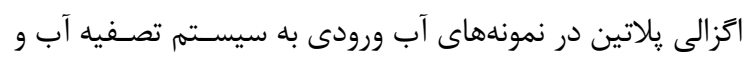

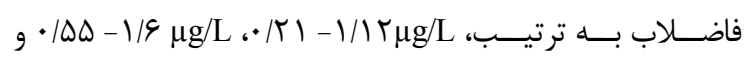

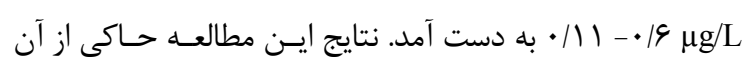

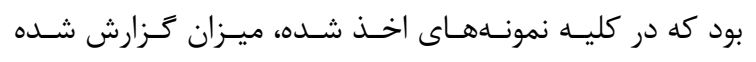

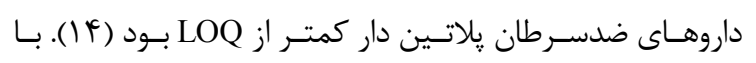

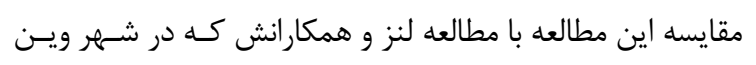


(Gas Chromatography - mass طيـف سـنجى جرمسى (s) spectrometry)

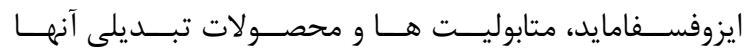

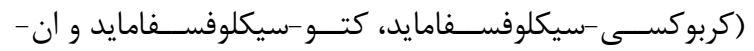

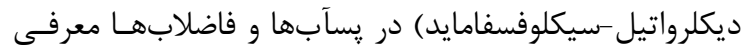
شد. روش ذكر شده در خصوص يسـآب بيمارسـتانى و يسـآب

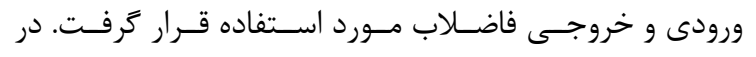

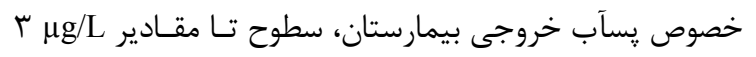

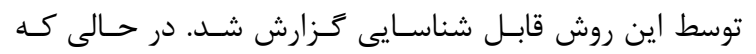

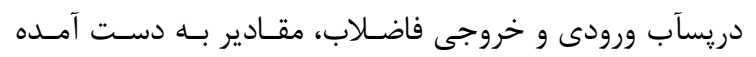

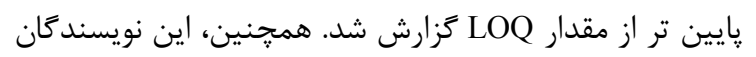
به ايجاد محصولات تبديلى احتمالى اشاره كردند و سه محصـول

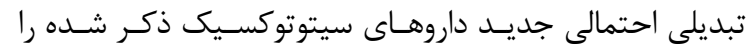

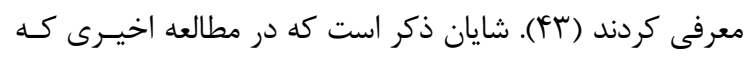

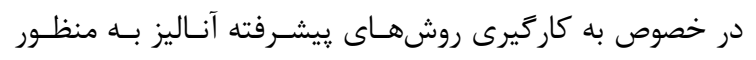

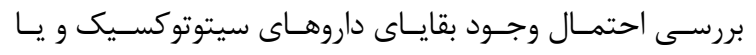
متابوليتهاى آنها در يسآب بيمارستانى و فاضـلابهــا در كشــور برزيل صورت گرفت، روشهـاى آنـاليز HPLC-FLD بــهـ همـراه solid phase extraction microextratcion مقــادير احتمــالى داروهــاى ضــد ســرطان دوكسوروبيســين،

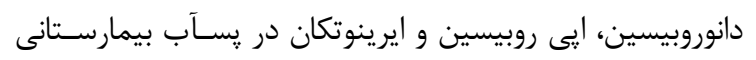

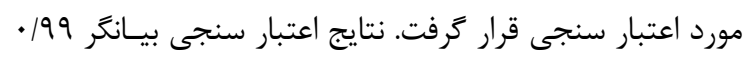

حذف زبالـههـاى سيتوتوكسـيك در رِّـآب بيمارسـتان مـورد

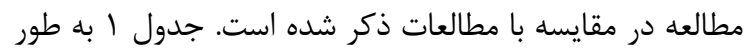

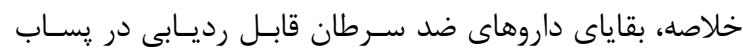
بيمارستانى در مطالعات مرور شده را نشان مى دهدد. بـان بكارگيرى روش هاى بيشرفته آناليز به منظور بررسى احتمال وجود بقاياى داروهاى سيتوتوكسيك و ياي متابوليت هاى آنها در يسآب بيمارستانى و فاضلابها نياز مبرم در خصوص ايجاد روشهاى آناليز تيشرفته كـه قـادر به تشخيص بقاياى داروهاى سيتوتوكسيك و متابوليتهاى آنها

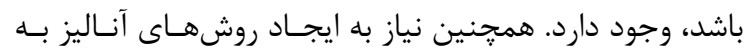
منظور تشخيص اثرات زيست محيطى تماس با بقاياى داروهاى

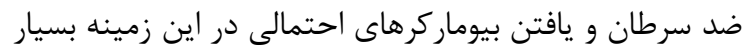

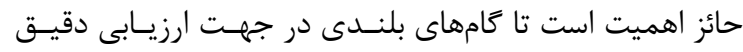

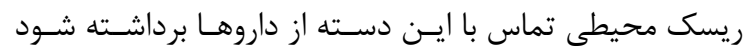

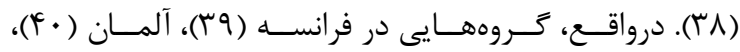

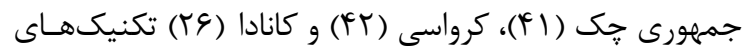
جديدى را ارائه كردهاند كه با استفاده از تلفيق - جمان phase extraction جرمى (LC-ESI(+/-)-MS/MS)، روشهاى حسـاس و دقيقى را به منظور اندازه گيرى ميزان باقى مانـده ايسن داروهـا ايجـاد

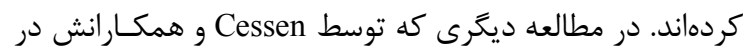

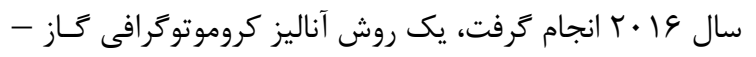

جدول ا. آلودگى پِاب بيمارستانى توسط داروهاى سيتوتوكسيك

\begin{tabular}{|c|c|c|c|c|}
\hline 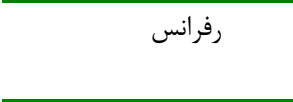 & غلظت به دست آمده & 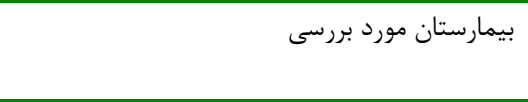 & كشور (شهر) & 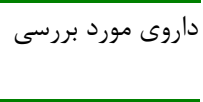 \\
\hline Kümmerer et al., 2010 & $r \cdot n g / L$ & بيمارستان آموزشى فرايبورى & آلمان (فرايبورگ) & \\
\hline Ferrando et al., 2014 & $r \cdot \mathrm{mg} / \mathrm{L}$ & تعدادى از بيمارستان هاى اسيانيا & اسيانيا & \\
\hline Yin et al., 2010 & $\cdots \mathrm{ng} / \mathrm{L}$ & ا آ بيمارستان در يكن & جين (يكن) & سيكلوفسفامايد \\
\hline Kümmerer et al;; 2010 & $r \cdot \varphi \cdot n g / L$ & بيمارستان آموزشى فرايبورى & آلمان (فرايبورگ) & \\
\hline Yin et al., 2010 & $|\Delta| \mathrm{ng} / \mathrm{L}$ & ا Y بيمارستان در پيكن & جين (يكن) & ايفسفامايد \\
\hline Ferrando et al., 2014 & $r \Delta-r \Lambda \quad \mathrm{mg} / \mathrm{L}$ & تعدادى از بيمارستان هاى اسيانيا & اسيانيا & \\
\hline Negreira et al., 2014 & \• ng/L & يك بيمارستان مركزى و بزرى در اسيانيا & 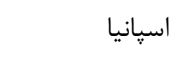 & تاموكسيفن \\
\hline Negreira et al., 2014 & r ng/L & يك بيمارستان مركزى و بزرگ در اسيانيا & 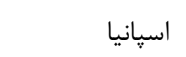 & \\
\hline Yin et al., 2010 & IV ng/L & ا اץ بيمارستان در يكن & جين (يكن) & متوتروكسات \\
\hline Mahnik et al., 2007 & $<\Lambda / 9-\mid r \mu / \Delta \mu \mathrm{g} / \mathrm{L}$ & بيمارستان آموزشى وين & اتريش (وين) & \\
\hline Weissbrodt et al., 2009 & $<\Delta-r \vee n g / L$ & بيمارستان مركزى سوئيس & سوئيس & \\
\hline Mullot et al., 2009 & $\cdot / \cdot 9-f \mu g / L$ & بيمارستانى در فرانسه & 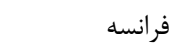 & وروراسيل \\
\hline Sadeghi et al., 2016 & $r G / \Lambda F-V F / 9 r \mu g / L$ & هفت مركز تخصصى و فوق تخصصى درمان سرطان . & 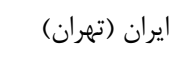 & \\
\hline Mahnik et al., 2007 & $<\cdot / r q-1 / T \Delta \mu \mathrm{g} / \mathrm{L}$ & بيمارستان آموزشى وين & اتريش (وين) & دو كسوروبيسين \\
\hline Yin et al., 2010 & $10 \mathrm{ng} / \mathrm{L}$ & آ بيمارستان در يكن & جين (يكن) & آزاتيويراين \\
\hline Yin et al., 2010 & fr ng/L & ا إ بيمارستان در يكن & جين (يكن) & اتويوزايد \\
\hline
\end{tabular}


در خصـوص دو داروى سـيس هيلاتسين و كربـويلاتين

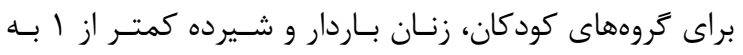

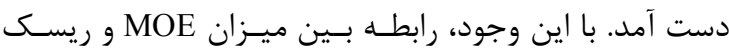

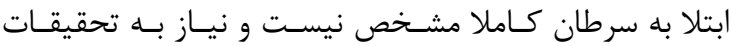

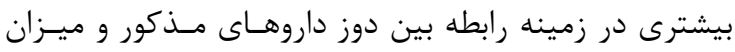

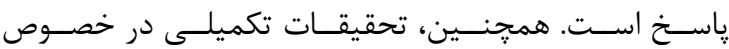

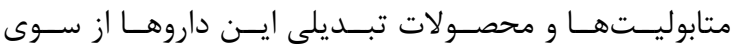

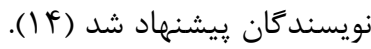
درواقع، مطالعات كوناكونى در نقاط مختلف جهان در خصـوص

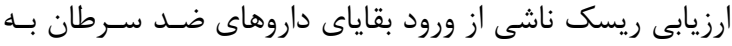

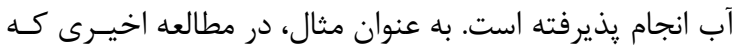

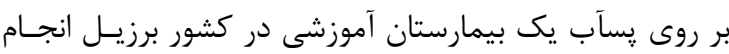
كرفت، داروهاى ضد سـرطان دوكسوروبيسـين، دانوروبيسـين، بردين

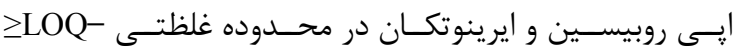

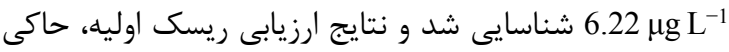

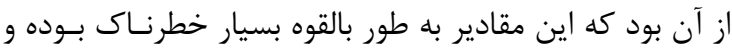

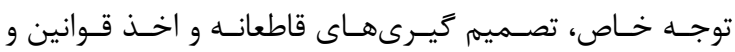

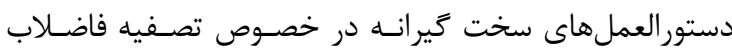

بيمارستانى مورد نياز است (F)

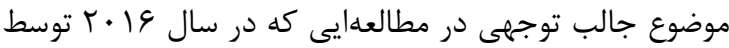

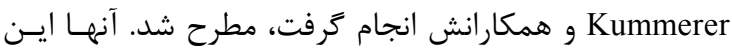

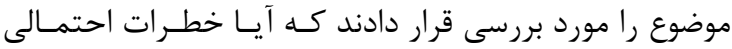
مربوط به وجود داروهاى سيتوتوكسيك در محيط با توجه به اله

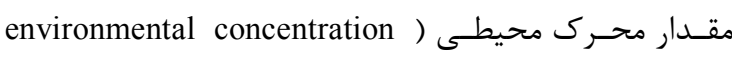
 ميزان

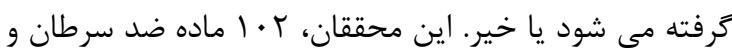
فعال را درمحيط شناسايى كردند. مطابق با بررسىهاى آنها، آنسا.

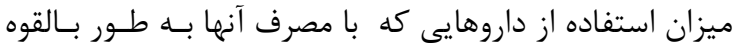

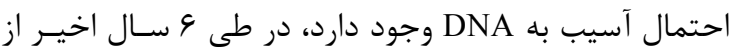

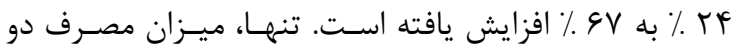

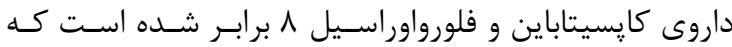

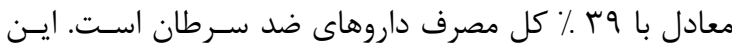

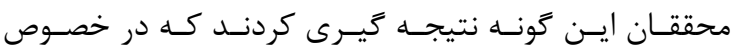
داروهايى كه بالقوه باعث آسيب به DNA مى شوند (داروهاى

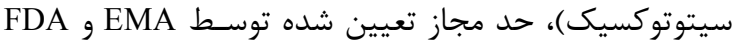

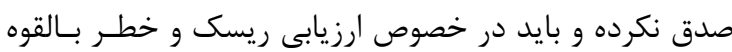

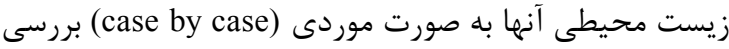

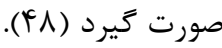

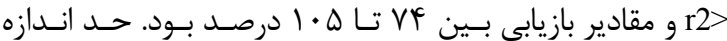
كيــرى (Limit of quantification)، استفاده از روش ذكر شده، وجود بقاياى داروهاى ضد سرطان در

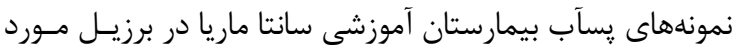

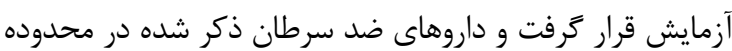

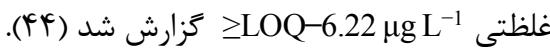
ارزيابى ريسك احتمالى ناشى از وجود بقاياى داروهاى

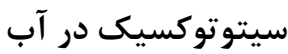
مطالعاتى در خصوص ارزيابى ريسك احتمالى وجـود داروهــاى

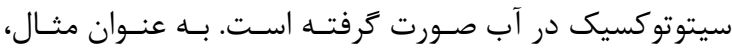

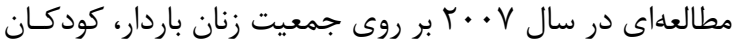

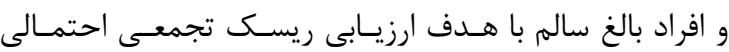

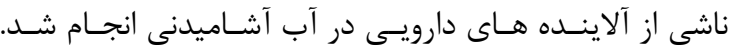

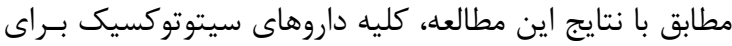
كروه زنان باردار و شيرده در دسته منع مصرف قرار دارد، مخَر

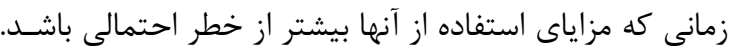

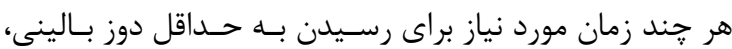

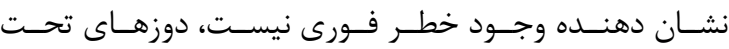

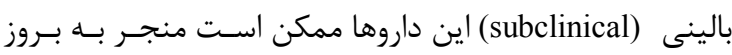
اثرات فيزيولوزيكى و مورفولوزيكى سلولى شود (هأ). به عنوان نمونه، داروهاى سيتوتوكسيك ممكن است بعد ازمـــتى منجــر

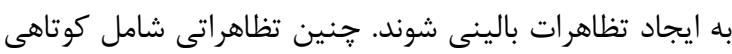

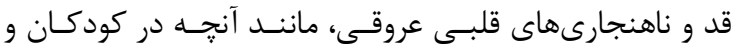

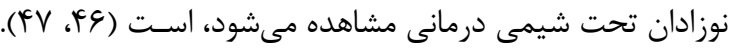

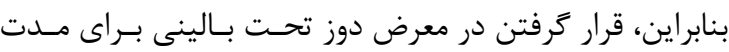

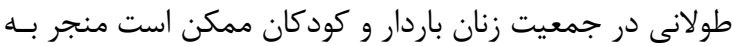
بروز تغييرات فيزيولوزيك طولانى مدت شود (هأ).

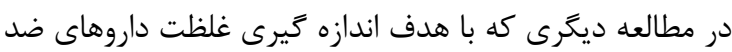
سرطان حاوى يلاتين در آب لوله كشى شهرستان قم در ايـران و ارزيابى ريسك احتمالى ناشسى از آن انجـام يـــيرفت، داروى دئي

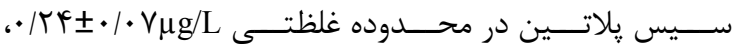

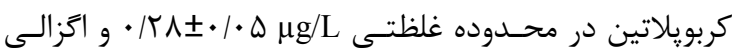

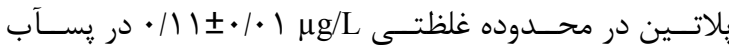

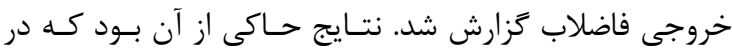

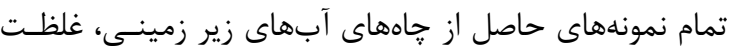

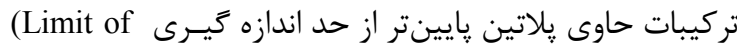
quantification)

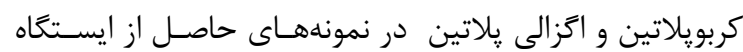

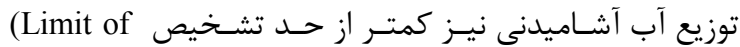

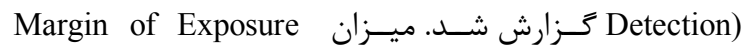


معمول تصفيه آب قادر به حذف اين دارو نيسـتند. در مطالعـهـ

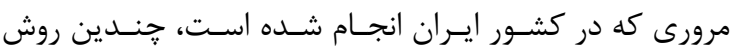
تركيبى حذف اين دارو مورد بررسى قرار گرفته اسـت. مطـابق

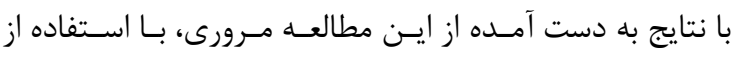

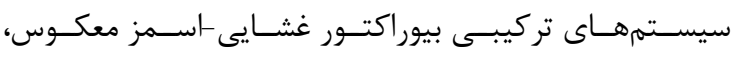
بيوراكتورغشايى -نانوفيلتراسيون، حذف بيشتر سيكلوفسـفامايد

$$
\text { قابل دسترسى است ( اله). }
$$

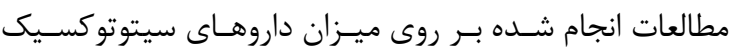

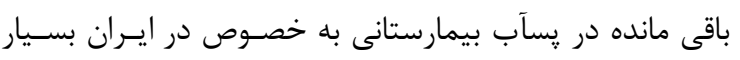

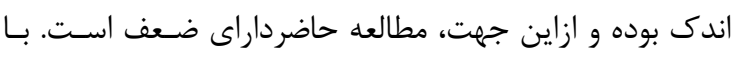

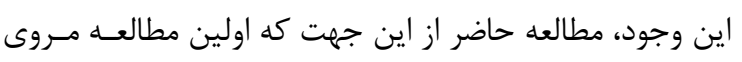

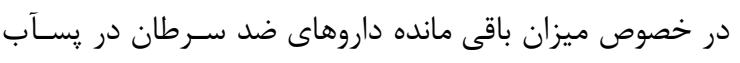

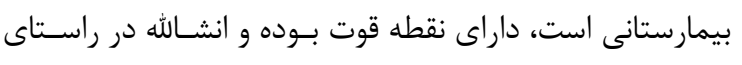
ير كردن شكاف هايى كه در دانش موجود در اين زمينه وجـود دئي

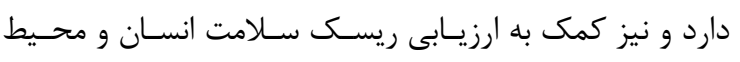
زيست، نقش موثرى را خواهد داشت. از آنجايى كـهـ يـارهاى از

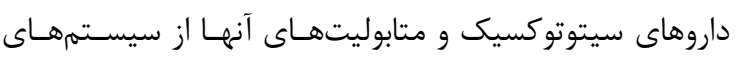

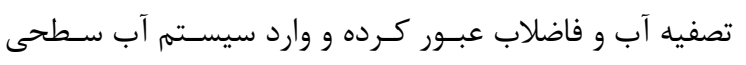

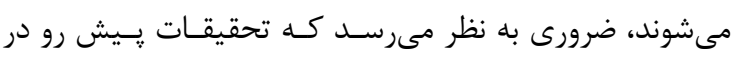
راستاى زدودن بقاياى داروهاى سيتوتوكسيك و كاهش ميـزان

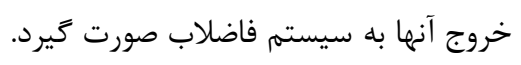

\section{نتيجه گَيرى}

مديريت دفع زباله هاى يزشكى، يكى از مهمتـرين و خطيرترين

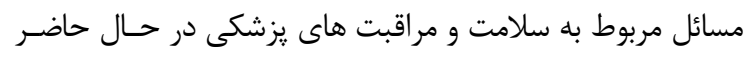
در كشور است. ضايعات بيمارسـتانى و على الخصـوص ضـايعات سيتوتو كسيك، طيف گستردهاى ازخطرات مربوط به سـلامتى و

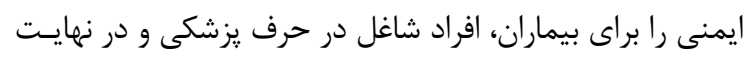

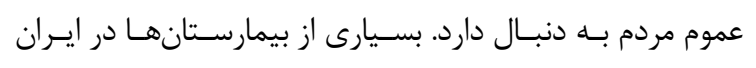

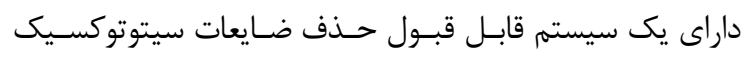

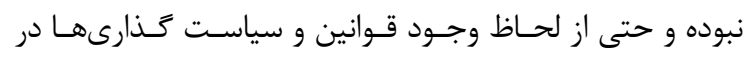

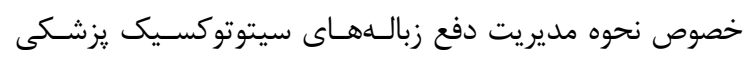

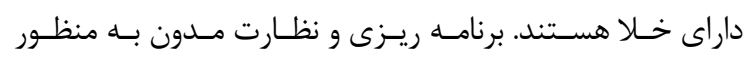

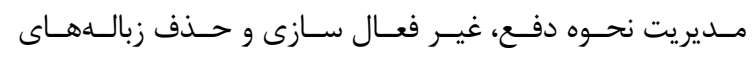
بيمارستانى و على الخصوص زبالههاى سيتوتوكسيك و اطمينـان

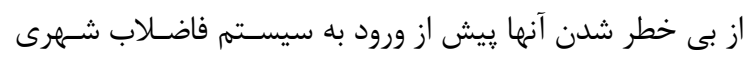

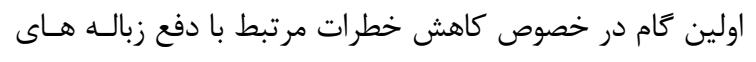

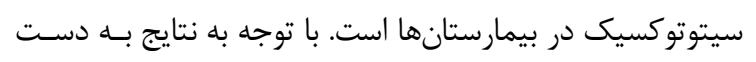

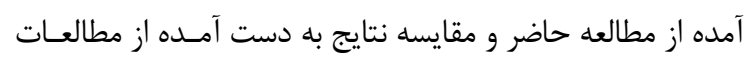

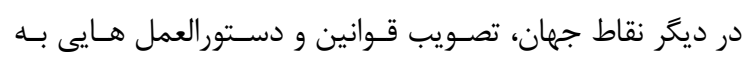

\section{غيرفعال شدن داروهاى سيتوتوكسيك توسط سيستمه هاى تصفيه فاضلاب}

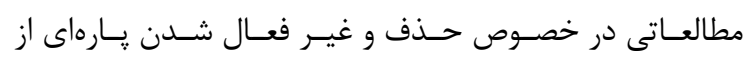

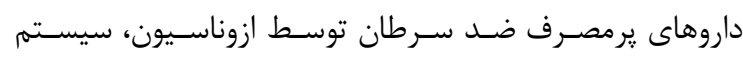

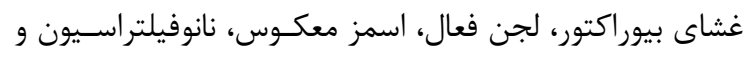

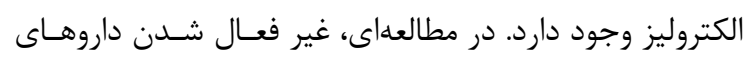

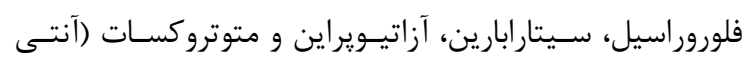

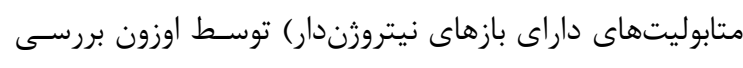

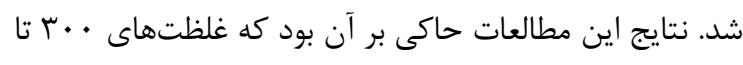

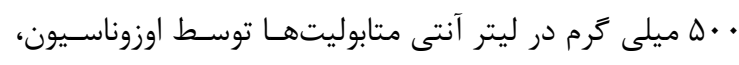

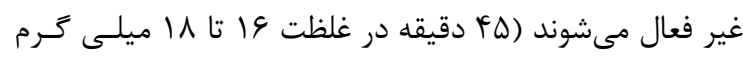

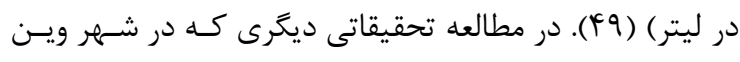

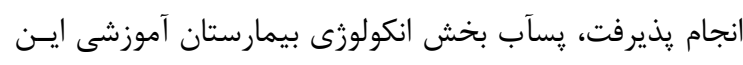

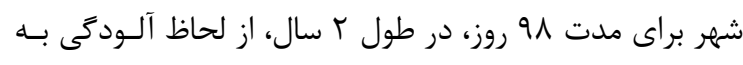

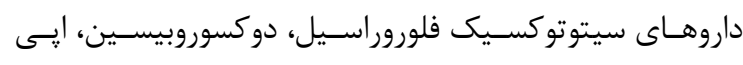

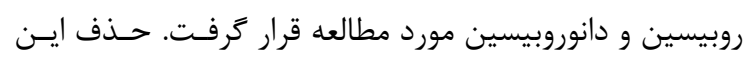

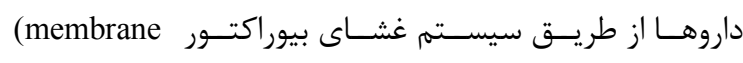

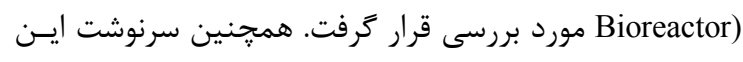

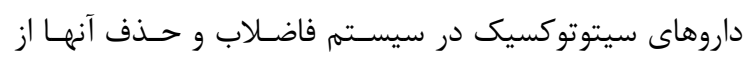
طريق سيستم لجن فعـال (activated sludge) و نيـز بـا مـواد

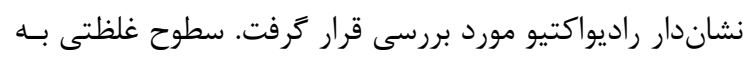

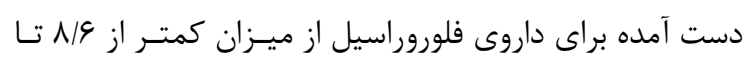

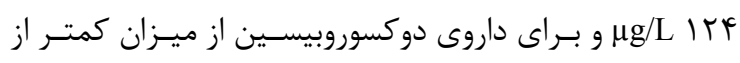

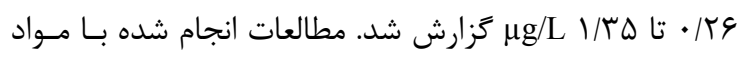

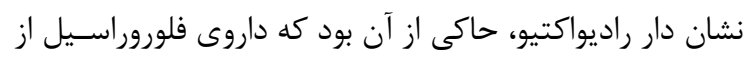

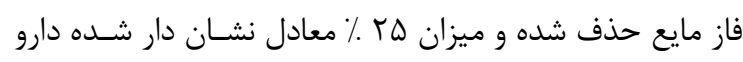

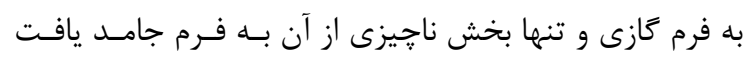

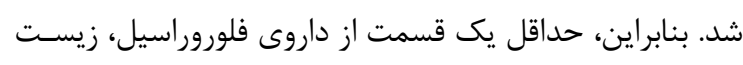

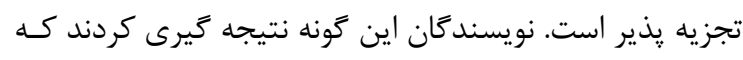

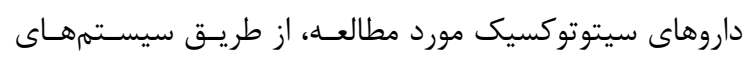

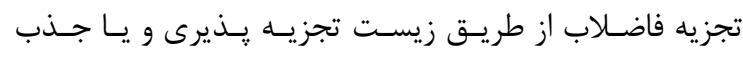

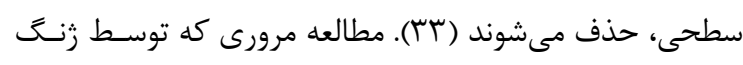

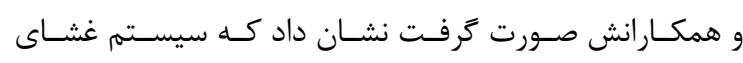

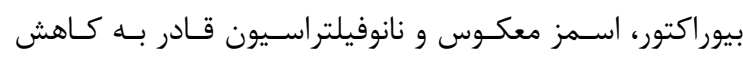

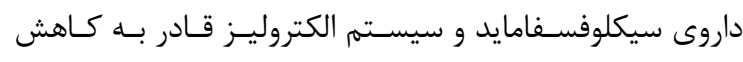
داروى متوتروكسات است. همجنين UV و UV كاهش متوتروكسات و سيكلوفسفامايد در آب خـالص، ديـونيزه

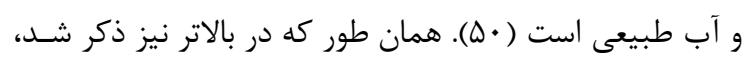

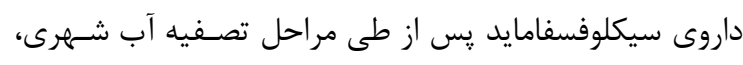

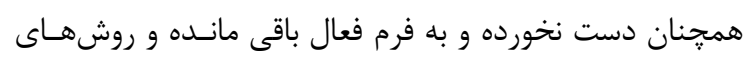




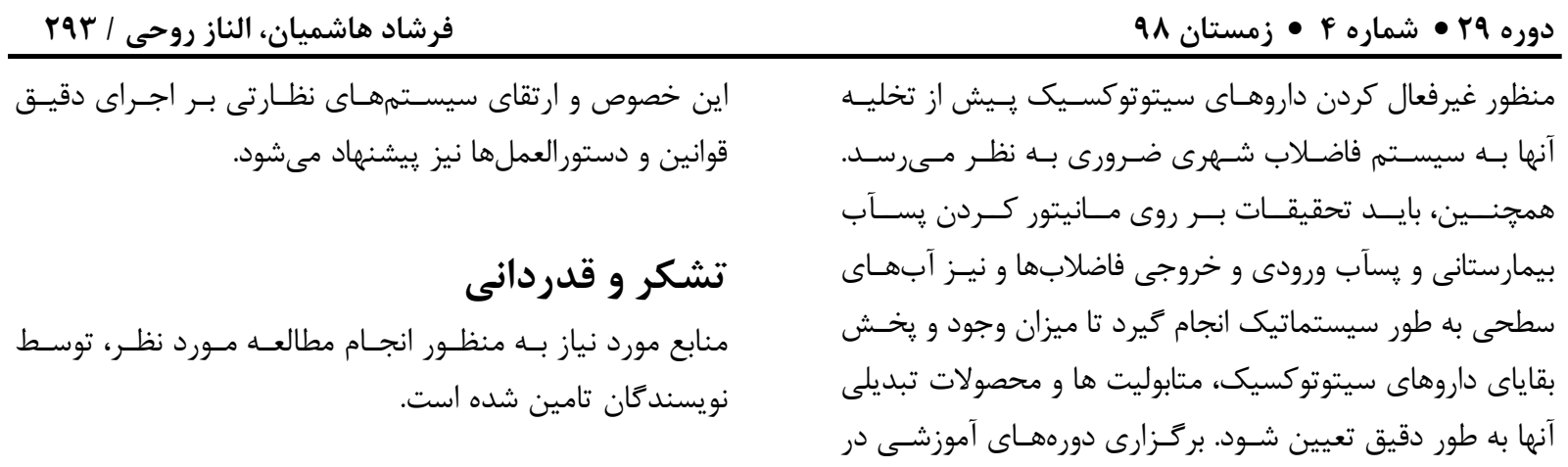

\section{REFERENCES}

1. Amouei A, Asgharnia H, Fallah H, Faraji H, Barari R. Characteristics of Effluent Wastewater in Hospitals of Babol University of Medical Sciences, Babol, Iran, Health Scope 2015;4:e23222 .[In Persian]

2. Farré M, Pérez S, Kantiani L, Barcelo D. Fate and toxicity of emerging pollutants, their metabolites and transformation products in aquatic environment. Sci Total Environ. 2008; 27: 991-1007.

3. Rowney NC, Johnson AC, Williams RJ. Cytotoxic drugs in drinking water: a prediction and risk assessment exercise for the thames catchment in the United kingdom. Environ Toxicol Chem. 2009;28:2733-43.

4. Kummerer K. Drugs in the environment: emission of drugs, diagnostic aids and disinfectants into wastewater by hospitals in relation to other sources. A review. Chemosphere 2001;45:957-969.

5. Aungst BJ. Novel formulation strategies for improving oral bioavailability of drugs with poor membrane permeation or presystemic metabolism. J Pharm Sci 1993;82:979-987.

6. Macpherson IRJ, Cassidy J. Challenges in combinational oncology studies. Pharm Med 2008;22:85-97.

7. Kortenkamp A, Faust M, Scholze M, Backhaus T. Low level exposure to multiple chemicals: reason for human health concerns? Environ Health Perspect 2007;115:106-114.

8. Jones O, Voulvoulis N, Lester JN. Human pharmaceuticals in wastewater treatment processes. Crit Rev Environ Sci Technol 2005;35:401-427.

9. Isidori M, Lavorgna M, Russo C, Kundi M, Žegura B, Novak M, et al. Chemical and toxicological characterisation of anticancer drugs in hospital and municipal wastewaters from Slovenia and Spain. Environ Pollut 2016;219:275-287.

10. Fuerhacker M, Mahnik SN, Lenz K, Weissenbacher N, Mader RM, Krenn P, et al. Hospital waste water: health risk for human and environment by cytostatic drug emissions? Part I: model calculation and chemical monitoring. BMC Pharmacol 2007;7:A69.

11. Jaafari J, Dehghani MH, Hoseini M, Safari GH. Investigation of hospital solid waste management in Iran. World Rev Sci Technol Sustain Dev 2015;12:111-125.

12. Chen M, Ohman K, Metcalfe C, Ikonomou M, Amatya P, Wilson J. Pharmaceuticals and endocrine disruptors in wastewater treatment effluents and in the water supply system of Calgary, Alberta, Canada. Water Qual Res J Can 2006;40:351-64.

13. Ebele AJ, Abdallah MA, Harrad S. Pharmaceuticals and personal care products (PPCPs) in the freshwater aquatic environment Emerg Contam 2017;3:1-16.

14. Ghafuri Y, Yunesian M, Nabizadeh R, Mesdaghinia A, Dehghani MH, Alimohammadi M. Platinum cytotoxic drugs in the municipal wastewater and drinking water, a validation method and health risk assessment. Human Ecologi Risk Ass 2017;24:1-13.

15. Johnson AC, Jurgens MD, Williams RJ, Kummerer K, Kortenkamp A, Sumpter JP. Do cytotoxic chemotherapy drugs discharged into rivers pose a risk to the environment and human health? An overview and UK case study. J Hydrol 2008;348:167-175.

16. Jobling S, Williams RJ, Johnson AC, Taylor A, Gross-Sorokin M, Nolan M, et al. Predicted exposures to steroid estrogens in UK rivers correlate with widespread sexual disruption in wild fish populations. Environ Health Perspect 2006;114:32-39.

17. Gross-Sorokin MY, Roast SD, Brighty GC. Assessment of Feminization of Male Fish in English Rivers by the Environment Agency of England and Wales. Environ Health Perspect. 2006;114:147-51.

18. Söffker M, Tyler CR. Endocrine disrupting chemicals and sexual behaviors in fish--a critical review on effects and possible consequences. Crit Rev Toxicol 2012;42:653-68. 
19. Nambirajan K, Muralidharan S, Roy AA, Manonmani S. Residues of diclofenac in tissues of vultures in India: a post-ban scenario. Arch Environ Contam Toxicol 2018;74:292-97.

20. Oaks JL, Gilbert M, Virani MZ, Watson RT, Meteyer CU, Rideout BA, et al. Diclofenac residues as the cause of vulture population decline in Pakistan. Nature 2004;427:630-3.

21. Buerge IJ, Buser HR, Poiger T, Müller MD. Occurrence and fate of the cytostatic drugs cyclophosphamide and ifosfamide in wastewater and surface waters. Environ Sci Technol 2006;40:7242-50.

22. O'Keefe TL. Cytotoxic drug contamination in hospital and municipal wastewater and its transfer to surface water. Pharma-Cycle, Inc, Middletown, RI; 2011:11.

23. Parrella A, Lavorgna M, Criscuolo E, Russo C, Isidori M. Estrogenic activity and cytotoxicity of six anticancer drugs detected in water systems. Sci Total Environ 2014;485:216-222.

24. Ghafuri Y, Nabizadeh R. Composition and quantity of cytotoxic waste from oncology wards: A survey of environmental characterization and source management of medical cytotoxic waste. Biosci Biotech Res Comm 2017;10: 438-44.

25. Kümmerer K, Al-Ahmad A. Estimation of the cancer risk to humans resulting from the presence of cyclophosphamide and ifosfamide in surface water. Environ Sci Pollut Res Int 2010;17:486-96.

26. Garcia-Ac A, Segura PA, Viglino L, Gagnon C, Sauvé S. Comparison of APPI, APCI and ESI for the LCMS/MS analysis of bezafibrate, cyclophosphamide, enalapril, methotrexate and orlistat in municipal wastewater. J Mass Spectrom 2011;46:383-90.

27. Steger-Hartmann T, Kümmerer K, Schecker J. Trace analysis of the anti-neoplastics ifosfamide and cyclophosphamide in sewage water by two step solid phase extraction and GC/MS. J Chromatogr 1996;A726:179-84.

28. Ferrando-Climent L, Rodríguez-Mozaz S, Barcelo D. Incidence of anticancer drugs in an aquatic urban system: From hospital effluents through urban wastewater to natural environment. Environmental Pollution 2014;216-223.

29. Lenz K, Koellensperger G, Hann S, Weissenbacher N, Mahnik SN, Fuerhacker M. Fate of cancerostatic platinum compounds in biological wastewater treatment of hospital effluents. Chemosphere 2007;69:1765-74.

30. Vyas N, Turner A. Sewell G. Platinum-based anticancer drugs in waste waters of a major UK hospital and predicted concentrations in recipient surface waters. Sci Total Environ 2014;493:324-29.

31. Negreira N, de Alda ML, Barceló D. Cytostatic drugs and metabolites in municipal and hospital wastewaters in Spain: Filtration, occurrence, and environmental risk. Sci Total Environ 2014;497-498:68-77.

32. Yin J, Shao B, Zhang J, Li K. A preliminary study on the occurrence of cytostatic drugs in hospital effluents in Beijing, China. Bull Environ Contam Toxicol 2010;84:39-45.

33. Mahnik SN, Lenz K, Weissenbacher N, Mader RM, Fuerhacker M. Fate of 5-fluorouracil, doxorubicin, epirubicin, and daunorubicin in hospital wastewater and their elimination by activated sludge and treatment in a membrane-bioreactor system. Chemosphere 2007;66:30-37.

34. Weissbrodt D, Kovalova L, Ort C, Pazhepurackel V, Moser R, Hollender J, et al. Mass flows of X-ray contrast media and cytostatics in hospital wastewater. Environ Sci Technol 2009;43:4810-7.

35. Mullot JU, Karolak S, Fontova A, Huart B, Levi Y. Development and validation of a sensitive and selective method using GC/MS-MS for quantification of 5-fluorouracil in hospital wastewater. Anal Bioanal Chem 2009;394:2203-12.

36. Sadeghi TS, Hashemian F, Afshar M. Exploring cytotoxic drugs residues in hospital effluents using high performance liquid chromatography [Dissertation]. Tehran: Faculty of Pharmacy, Tehran Medical Sciences, Islamic Azad University; 2016. P.30-35 [In Persian]

37. Hashemian F, Majdi M, Mohammadpour N. Cytotoxic deactivator system for hospital effluents. 2012. IR Patent No: 74272. Approved by Invention Committee of $\mathrm{MOH}$ and National Pharmaceutical Research Network.

38. Kosjek T, Heath E. Occurrence, fate and determination of cytostatic pharmaceuticals in the environment. Trends Anal Chem 2011;30:1065-1087.

39. Mullot JU, Karolak S, Fontova A, Huart B, Levi Y. Development and validation of a sensitive and selective method using GC/MS-MS for quantification of 5-fluorouracil in hospital wastewater. Anal Bioanal Chem 2009;394:2203-12.

40. Voigt K, Brüggemann R. Ranking of pharmaceuticals detected in the environment: aggregation and weighting procedures. Comb Chem High Throughput Screen 2008;11:770-82.

41. Zounková R, Odráska P, Dolezalová L, Hilscherová K, Marsálek B, Bláha L. Ecotoxicity and genotoxicity assessment of cytostatic pharmaceuticals. Environ Toxicol Chem 2007;26:2208-14. 
42. Smital T, Terzic S, Zaja R, Senta I, Pivcevic B, Popovic M, et al. Assessment of toxicological profiles of the municipal wastewater effluents using chemical analyses and bioassays. Ecotoxicol Environ Saf 2011;74:844-51.

43. Česen M, Kosjek T, Busetti F, Kompare B, Heath E. Human metabolites and transformation products of cylophosphamide and ifosfamide: analysis, occurrence and formation during abiotic treatments. Environ Sci Pollut Res Int 2016;23:11209-23.

44. Souza DM, Reichert JF, Martins AF. A simultaneous determination of anti-cancer drugs in hospital effluent by DLLME HPLC-FLD, together with a risk assessment. Chemosphere 2018;201:178-188.

45. Collier AC. Pharmaceutical contaminants in potable water: Potential concerns for pregnant women and children. Eco Health 2007; 4:164-171.

46. Mone SM, Gillman MW, Miller TL, Herman EH, Lipshultz SE. Effects of environmental exposures on the cardiovascular system: Prenatal period through adolescence. Pediatrics 2004;113:1058-1069.

47. Chow EJ, Friedman DL, Yasui Y, Whitton JA, Stovall M, Robison LL, et al. Decreased adult height in survivors of childhood acute lymphoblastic leukemia: A report from the childhood cancer survivor study. J Pediatr 2007;150:37075.

48. Kümmerer K, Haiß A, Schuster A, Hein A, Ebert I. Antineoplastic compounds in the environment—substances of special concern. Environ Sci Pollut Res Int 2016;23:14791-804.

49. Rey RP, Padron AS, Leon LG, Pozo MM, Baluja C. Ozonation of cytostatics in water medium. Nitrogen bases. Ozone Sci Eng 1999;21:69-77.

50. Zhang J, Chang VWC, Giannis A, Wang J-Y. Removal of cytostatic drugs from aquatic environment: A review. Sci Total Environ 2013;44: 281-298.

51. Khodkar A, Khoram Nezhadian S, Pendashte A. A review on elimination methods of anti-cancer drugs from effluents. Proceedings of the first international congress on environment; 2016 Feb 20; Tehran, Iran. 